\title{
Dutch lessons in forensic psychiatry
}

\author{
A senior registrar tours the Pieter Baan Centre and other \\ secure facilities in The Netherlands*
}

\author{
Jeyabala Balakrishna
}

\begin{abstract}
Dutch forensic psychiatry provides services for mentally disordered offenders which centre around a legal measure called the TBS order. Specialised units deal separately with assessment and treatment. The system appears to work in the context of a small and wealthy country and a criminal justice system which differs from the English system. This paper describes the key features of the secure units, examines the conceptual issues and complications of the Dutch system, and considers lessons for psychiatric and legal approaches to the problem of psychopathy in Brttain, in particular the new hybrid order.
\end{abstract}

The Ministry of Justice in The Netherlands operates a collection of therapeutic units for mentally disordered offenders. The court remands particular offenders to an assessment unit, the Pieter Baan Centre, which recommends the need for a TBS order - terbeschikkingstelling ('to dispose of). If this order is imposed upon conviction, a selection unit will determine allocation to one of the many TBS clinics.

The TBS order is imposed by court on a person who commits a serious crime while suffering from 'defective development or pathological disorder of his mental faculties' (i.e. 'defective development' of personality or intellect; 'pathological disorder' includes psychosis). Its function is to protect society from unacceptably high risks of recidivism, through detention in a TBS clinic. It is usually of indefinite duration, imposed for two years in the first instance, extended on yearly or two-yearly periods, and subject to specified rules, psychiatric review and right of appeal.

The Dutch Government's Memorandum (Ministry of Justice, 1994) clarifies the position of TBS:

*.B. visited The Netherlands on the John Hamilton Fellowship awarded by the Royal College of Psychiatrists.
"It is distinguished from confinement in a psychiatric hospital by a restriction of the danger criterion to the concrete threat to others, the seriousness of the crime committed. . . . [it is] distinguished from long-term imprisonment in that the offender is deemed to be not responsible or to have $r$ ly diminished responsibility ... and in that its primary objective is to reduce the future threat by treatment seeking to effect a structural change in behaviour".

Dutch law determines criminal responsibility on a five-point scale rather than the British allor-nothing approach.

The TBS order is aimed at motivating the person to undergo treatment during custodial care. Typically, a convicted prisoner serves onethird of his penal sentence before moving to a TBS clinic, but the order can be imposed without a penal component. Assessment and treatment are strictly separated in the TBS system.

\section{Assessment - at the Pieter Baan Centre}

The Pieter Baan Centre (PBC) in Utrecht is named after the psychiatrist who founded the Centre in 1949. Professor Baan was one of a trio of influential academics in the 1950s - the other two being Kempe, a criminologist and Pompe, a lawyer-who promoted the so-called Utrecht School, which emphasised an individualising approach to the mentally disordered offender in the criminal justice system (Moedikdo, 1976).

The assessment of the remanded prisoner is conducted by a multi-disciplinary team of psychiatrist, psychologist, social worker, sociotherapist and jurist. This remand for assessment occurs if the offence is serious or unusual in nature, if there is continuing recidivism or if there are particular psycho-social issues.

The seven-week assessment seeks to answer two key questions:

(a) Did the remanded prisoner suffer from mental disturbance at the time of the 
offence which diminished his responsibility for his actions?

(b) Does the remanded prisoner present with a degree of dangerousness and risk of reoffending which would require a TBS order to protect others from him?

The PBC has four departments (wards), each housing up to eight remanded prisoners. The remanded prisoner is called observandus - "he who is being observed'. Emphasis is on a psychodynamic understanding of the observan dus. Behaviour is observed in groups, in informal interactions, in occupational therapy and in recreational activities. The medical model does not predominate, assessment does not aim to reach a psychiatric diagnosis, and treatability is not a key issue.

The group leaders, 'sociotherapists', are the unique discipline in the PBC, who work in shifts on the departments. There are three group leaders to eight observandi. They undergo formal training in 'institutional work', involving sociology and psychology. Their backgrounds vary probation officers, prison officers, social workers and nurses.

The jurists are lawyers who collate and summarise all information pertaining to the legal process (i.e. facts of the case, witness statements, previous convictions, probation report etc.). This will then assist the investigations of the other professionals.

Regular multi-disciplinary staff meetings review the progress of each assessment. The final meeting delivers the recommendations of the PBC and the voluminous report to the court. The team decides by consensus on the degree of responsibility of the observandus and the risk of harm to persons or property.

The PBC produces some 200 reports a year. The majority of observandi are male, a third are first offenders, and about three-quarters have previous psychiatric admissions (Koenraadt, 1992).

\section{Selection and treatment}

The convicted prisoner who receives a TBS order is assessed in the Selection Institute (which sits adjacent to the PBC in Utrecht). The Institute allocates the prisoner according to the emphasised modalities of treatment in the different TBS clinics and the nature of mental disorder. For example, the van der Hoeven Clinic in Utrecht has a therapeutic community, the van Mesdag Clinic in Groningen is run on analytical lines. while the Pompe Clinic in Nijmegen emphasises a behavioural regime. (There are six TBS clinics in The Netherlands.) The TBS clinics are spacious, with state-of-the-art physical security, modern occupational and recreational facilities (includ- ing gymnasia and swimming pools), and good staffing across the disciplines.

The FOBA (Forensische Observatie en Begeleidings Afdeling) in the prison service is a psychiatric intensive care unit, located in the maximum security prison in Over-Amstel. The FOBA deals with acute psychosis and severe behavioural problems referred from the prisons and TBS clinics.

In the health service, there are forensic psychiatric clinics (similar to British medium secure units), and forensic psychiatric departments (similar to close supervision units) situated on psychiatric hospital sites. The clinics deal primarily with organic and functional mental disorders. Some TBS prisoners, usually with dual diagnoses, are treated here. The departments are typically small wards with limited security. They do not usually accept TBS prisoners. However, they contain a mixture of people with psychosis and personality disorders with significant forensic histories.

\section{Lessons to learn}

Strachan (1982) comments on the assessment process in the PBC: "the pressures to find some abnormality after seven weeks of observation for the court is an interesting complication of the Dutch approach". Strachan says that some observers see this process as "elaborate and extravagant", and he wonders whether a shorter period of observation with the same professional resources might work equally well. The TBS system promotes the independent and impartial position of the forensic mental health professional. Hence assessment and treatment are kept apart. Mooij (1991) emphasises assessment and reporting as the essence of forensic psychiatry, where legal questions lead to answers which have judicial consequences. The Reed Working Group on Psychopathic Disorder (Department of Health, 1994) were attracted to the structured assessment model of the Dutch system. They proposed "hospital assessment centres" and "prison selection centres" to deal with offenders who might have serious personality problems.

I would argue that the Dutch model works because it operates in a system where there is greater compatibility between legal and psychiatric functions, where the mental state at the time of offence is focused upon, and where a discussive rather than adversarial legal process determines disposal. These circumstances do not exist in Britain, where hospital-based forensic psychiatrists who have responsibility for the treatment of mentally disordered offenders need to be able to also assess, in order to ensure appropriate use of hospital services. 
The Dutch have difficulty describing the TBS clinics as either prisons or hospitals, implying a unique blend of the two models. Is this possible? Peay (1993) argues against the labels of 'treatment' and 'punishment', and supports pluralism. In examining three models of criminal justice-crime control through punishment, due process to ensure safeguards in fairness, and the medical model of rehabilitation - Peay proposes "balancing the peculiar merits of each model to provide one cohesive system capable of dealing with the particular conditions of all".

One might see TBS clinics as an attempt to 'treat' criminal behaviour in the hope of reducing risk of re-offending. This is invariably a longterm commitment. The need to find meaningful measures of efficacy in treatment is a question which continues to be addressed.

The TBS system is expensive. Strachan (1982) points to the cost implications of adopting this model in Britain. Koenraadt (1993) states that the system probably works because of "the small population size and the relative wealth of the country, and could not be replicated in larger. more heavily urbanised countries with less commitment to public spending".

The Dutch system is landed with the burden of growing numbers of convicted prisoners waiting to 'receive treatment'. The courts, faced with limits on punitive sentencing, appear to use the TBS order as a means of detaining dangerous offenders for as long as possible.

A further concern is the growing numbers of offenders with functional disorders ending up on TBS clinics designated for psychopaths, a probable consequence of psychiatric hospital closures and deinstitutionalisation. There are limited hospital-based forensic psychiatric services for TBS prisoners who are psychotic. One might argue that the extensive investment in addressing psychopathy has created an assessment and treatment environment which the mentally ill cannot fit into.

The Crime (Sentences) Act 1997 contains the so-called hybrid order which combines a "hospital direction' with a prison sentence based on public protection criteria, rather similar to the TBS order. In my view, the ethical, legal and health service cost implications, as described by Eastman (1997), arise partly as a result of the situation of parallel models of prison and hospital.

\section{Comments}

The Dutch forensic psychiatry services appear to work well in the context of The Netherlands's size and economic situation, and the interface between its judicio-legal framework and psychiatry. These circumstances differ in Britain, and a replication of the Dutch model cannot easily occur.

We should examine the possibility of a pluralistic approach to mentally disordered offenders - not isolating this group, avoiding categorisation into 'treatment' or 'punishment' and considering provisions for the "partly mad" and "partly bad" in both prison and hospital services (Peay, 1993).

Should Britain adopt the Dutch system of TBS clinics, which appear to sit between the prison and hospital models? This might work with the original proposal of the hybrid order applying only to psychopathic disorder as recommended by the Reed Working Group (1994). If the hybrid order is extended to all categories of mental disorder, the Dutch experience suggests that judicial response to such sentencing options would overwhelm the health services.

Our health services will have to consider if they should have primary responsibility for providing treatment for psychopathic offenders. In considering specialised units for these individuals, we must guard against hospital-based services for the mentally ill offenders becoming poor cousins.

Finally, if we do set up such specialised units, these units should provide both assessment and treatment. We should consider the opportunity for a naturalistic approach to researching outcome, as advised by Dolan \& Coid (1993): "to consider which patients benefit from which setting at which time in their recovery". They add that this approach could build on existing resources and identify resources for expansion, towards greater efficiency in and better understanding of dealing with the problem of psychopathy.

\section{Acknowledgements}

I am greatly indebted to Jan Scheffer, Director of Observations and Reporting at the PBC, for his constant support and profound inspiration. Thanks also to Professor Mooij, Professor Raes, Dr Koenraadt, Jack Oudejans, Kess Lemke, all group leaders on Afdeling $A$, the efficient secretaries, Els the librarian and officials from the Ministry of Justice.

\section{References}

DEPARTMENT OF HEALTH (1994) Report of the Working Group on Psychopathic Disorder (Reed Report). London: HMSO.

Dolan, B. \& CoID, J. (1993) Psychopathic and Antisocial Personality Disorders: Treatment and Research Issues. London: Gaskell.

EASTMAN, N. L. G. (1997) Hybrid justice: proposals for the mentally disordered in the Crime (Sentences) Bill. The ethical, legal and health service cost implications. Psychiatric Bulletin. 21. 129-131. 
KOENRAADT, F. (1992) The individualising function of forensic multidisciplinary assessment in a Dutch residential setting: The Pieter Baan Centre experience. Intemational Journal of Law and Psychiatry. 16, 195203.

- (1993) Forensic mental hospitals according to Dutch standards. Criminal Behaviour and Mental Health, $\mathbf{3}$. 322-334.

MINISTRY OF JUSTICE (1994) TBS: A Special Hospital Order of the Dutch Criminal Code. The Hague: Ministry of Justice.

MoEDIKDO, P. (1976) De Utrechtse School van Pompe, Baan en Kempe. In Recht, Macht en Manipulatie (ed. C. Kelk), pp. 90-154. Utrecht/Antwerp: Spectrum.

Moow, A. W. M. (1991) Forensic-psychiatric reporting in a residential context. In Considering the Accused (eds A Mooij, F. Koenraadt \& J. Lommen-van Alphen), pp. 9 19. Amsterdam: Swets en Zeitlingen.
PEAY, J. (1993) A criminological perspective - the influence of fashion and theory on practice and disposal: life chances in the criminological tombola. In The Mentally Disordered Offender in an Era of Community Care (eds W. Watson \& A. Grounds). Cambridge: Cambridge University Press.

Strachan, J. G. (1982) Psychiatric assessment of the dangerous offender in The Netherlands. Medicine. Science and the Law, 22, 16-20.

Jeyabala Balakrishna, Senior Registrar in Forensic Psychiatry, Springfield University Hospital, London SW17 7DJ

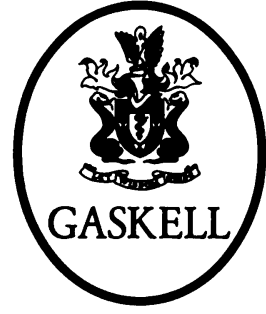

\title{
Seminars in Practical Forensic Psychiatry
}

\author{
Edited by Derek Chiswick \& Rosemary Cope
}

Seminars in Practical Forensic Psychiatry is a concise account of the specialty from a strongly practical perspective. It systematically describe the relationship between psychiatric disorders and offending, with detailed discussion of the criminal justice system, court proceedings, mental health legislation, dangerousness, prison psychiatry, and civil issues. There are boxes summarising key points, illustrative case examples, and sample court reports. It is up-to-date, with references to the Reed Report, the Clunis Inquiry, supervision registers and recent legislation. Career guidance and a chapter on ethical issues are included. This book will be invaluable for general psychiatrists and for trainees in forensic psychiatry, as well as those other health and social work professionals having contact with mentally disordered offenders, and those who are part of the criminal justice system. Price $E$ 17.50, 359pp., 1995, ISBN 0902241788

Available from good bookshops and from the Publications Department, Royal College of Psychiatrists, 17 Belgrave Square, London SWIX 8PG (Tel. 017I-235 235I, extension 146) 